\title{
Population genetic structure and historical demography of the population of forest elephants in Côte d'Ivoire
}

\author{
Jean-Louis Kouakou ${ }^{1}$. Sery Gonedelé-Bi ${ }^{1,2, *}$ \\ ${ }^{1}$ Laboratoire de Biotechnologie, Agriculture et Valorisation des Ressources biologiques, Université Félix \\ Houphouët-Boigny d'Abidjan-Cocody, Côte d'Ivoire \\ ${ }^{2}$ Centre Suisse de Recherches Scientifiques en Côte d'Ivoire, Adiopodoumé, Côte d'Ivoire
}

Corresponding author: Sery GONEDELE-BI

E-mail: sery.gonedele@univ-fhb.edu.ci

ORCID iD : 0000-0002-2760-2795

Postal address: 22 BP 582 Abidjan 22, Côte d'Ivoire

Tel.: (+225) 0103488923 


\begin{abstract}
The population of forest elephant has continuously declined in Côte d'Ivoire and, the remaining population largely consists of small populations that are fragmented and isolated. No data actually exist on the level of genetic diversity and population genetic structure of current forest elephant populations in Côte d'Ivoire need to be highlighted. In this sense, determining genetic diversity and the underlying mechanisms of population differentiation is crucial for the initiation of effective conservation management.

Forest elephant dung samples were collected in three forest reserves (FR) in Côte d'Ivoire. The total genomic DNA was extracted from these samples, A total of 101 sequences of the mitochondrial DNA control region measuring 600 base pair and 31 haplotypes were obtained. A haplotypic diversity ranging from $0.655 \pm 0.050$ at Bossématié and $0.859 \pm 0.088$ at Port Gauthier was obtained. More than half (16 of 31) of the haplotypes observed were singletons and only the Dassioko and Port Gauthier FRs shared the same haplotypes. The strong genetic connectivity between forest elephant populations of the Dassioko and Port Gauthier FRs is supported by the grouping of these populations into a single cluster by Bayesian analysis and principal component analysis. Although populations of Loxodonta cyclotis still exhibit relatively high genetic diversity, habitat fragmentation has already affected the genetic variability of current populations. Urgent measures including the reinforcement/establishment of genetic corridors and the strengthening of protection measures need to be undertaken to save the remaining populations.
\end{abstract}

Keywords: Côte d'Ivoire, genetic structure, mitochondrial DNA, historical demography, Loxodonta cyclotis, non-invasive sampling 


\section{Abbreviations}

IUCN International Union for the Conservation of Nature

DMSO Dimethyl sulfoxide

CTAB Cetyl Trimethyl Ammonium Bromide

mtDNA Mitochondrial DNA

PCR Polymerase chain reaction

BSA Magnesium chloride

PCA Principal component analysis

Hd Haplotype diversity

HKY $+\mathrm{G}$ Hasegawa, Kishino, and Yano with Gamma distribution model of nucleotide substitution

FR Forest Reserve

AMOVA Molecular variance

UPGMA Unweighted Pair Group Method with Arithmetic mean 


\section{Introduction}

African Forest Elephants formerly occurred across the entire humid forest area of western and central Africa, and currently are found in 20 countries. Their range is decreasing and is highly fragmented in western Africa where seven range countries are reported to have fewer than a hundred African Forest Elephants each [1,2]. Combined effect of increasing human population growth, habitat loss and fragmentation and continuous poaching for ivory have deciphered the population of forest elephant. These threats are particularly worst in West Africa where even protected area that serve has refuges for these large mammals are encroached for farming in the absence of effective control measure [3-5]. Indeed, forest elephant habitat in West Africa has been fragmented, with most populations under significant pressure from human population growth, the spread of agriculture and herding around and within parks [6]. The level of threats affecting forest elephant has held to the upgrade of the level of conservation status from Endangered to Critically Endangered by the International Union for the Conservation of Nature (IUCN) [2].

In Côte d'Ivoire, of an early population estimate of 3050 individuals throughout the country [6], the population of forest elephant has continuously declined. The remaining population is highly fragmented and largely consists of nominally protected national parks and forest reserves. Recent population estimate by Kouakou et al. [5] indicate that these population consists of four fragmented and isolated populations. In these small populations, genetic drift and increased inbreeding can reduce genetic diversity $[7,8]$. The viability of the remaining population is then questionable. No data actually exist on the level of genetic diversity and population genetic structure of current forest elephant populations of Côte d'Ivoire and the genetic conservation status of this species need to be highlighted. In this sense, determining genetic diversity and the underlying mechanisms of population differentiation in impacted populations is crucial for the initiation of effective conservation management [9].

Mitochondrial control region has been widely used for the study of population genetic structure of species because it is more variable than other coding region and its lack recombination $[10,11]$. In this study, we used the mitochondrial DNA (mtDNA) control region to evaluate genetic diversity, the population genetic structure, and population demographic history of forest elephant in Côte d'Ivoire. The viability of these populations, their connectivity, and the existence of any genetic signatures were determined for the effective conservation and management of the remaining population of forest elephant in Côte d'Ivoire. In particular, it was important to determine whether observed reduction in population size was accompanied by depletion in levels of genetic diversity and also to detect genetic signatures of past demographic changes coupled with the effect of recent human induced disturbance.

\section{Material and methods}

\section{Samples collection}

From 07 to 30 October 2019, a total of 158 dung samples of forest elephant were collected at stage 1 of decompositions (dung pile intact, very fresh, and moist, with odour) in the Bossématié, Dassioko and Port-Gauthier Forest Reserves (FR) respectively located in the rainforest area in Côte d'Ivoire. Samples were stored into $20 \%$ Dimethyl sulfoxide (20\% DMSO) [12] at room temperature until transportation into a laboratory where they were stored at $-80{ }^{\circ} \mathrm{C}$.

\section{DNA extraction, PCR and sequencing}

Total genomic DNA was extracted from dung samples following the standard Cetyl Trimethyl Ammonium Bromide (CTAB) method [13] optimized by our in house protocol (supplement material on request) Primer pairs LafCR1 F: 5'-GTATAAGACATTACAATGGTC-3' $(10 \mu \mathrm{M})$ and LafCR2 R: 5'-AGATGTCTTATTTAAGAGGA-3' [14], were used to amplified 
approximately 600 base pairs (bp) of the mtDNA segment located in the hypervariable I of the control region. Polymerase chain reaction (PCR) was performed in a total volume of $50 \mathrm{~mL}$ reactions containing $1 \mu \mathrm{l}$ of genomic DNA $(338,15 \pm 528,54 \mathrm{ng} / \mathrm{uL}), 25 \mu$ l Quick-Load one Taq $2 \mathrm{X}$ Master Mix with Standard Buffer (New ENGLAND Biolabs, USA), $1 \mu$ l of Dimethyl sulfoxide $(10 \%)$ (Eurolabs, France), $1 \mu \mathrm{l}$ of magnesium chloride $(\mathrm{MgCl} 2)$ (New ENGLAND Biolabs, USA) $(25 \mathrm{mM}), 4 \mu \mathrm{l}$ of Bovin serum albumin (BSA) (SIGMA-ALDRICH, Germany) $(10 \%), 1 \mu \mathrm{l}$ of each primer $(10 \mu \mathrm{M})$ and $15 \mu \mathrm{l}$ volume Ultrapure water $\left(\mathrm{H}_{2} \mathrm{O}\right)$. This mixture was processed in the thermalcycler Techne TC-512 for PCR reactions at different successive temperature cycles. A total of 40 cycles were performed. Each cycle consists respectively of an initial denaturation at $95^{\circ} \mathrm{C}$ for $5 \mathrm{~min}$, followed by denaturation at $95^{\circ} \mathrm{C}$ for 30 seconds, a hybridization phase at $38.4^{\circ} \mathrm{C}$ for 45 seconds and an elongation at $72{ }^{\circ} \mathrm{C}$ for $30 \mathrm{~s}$, then a final termination cycle at $72{ }^{\circ} \mathrm{C}$ for $5 \mathrm{~min}$ and finally a cooling phase at $4^{\circ} \mathrm{C}$.

DNA sequencing was performed by BGI BIO-SOLUTIONS HONGKONG CO., LIMITED company following the techniques of Sanger et al. [15].

\section{Data analyses}

A total of 101 sequences of mitochondrial control region generated were aligned using the CLUSTAL X program [16] with the default settings and verified by eye. The programme DnaSP 6.11 .01 [17] was used to calculate genetic diversity indices (number of segregating sites $(S)$, number of haplotypes $(N h)$, haplotype diversity $(h)$, and nucleotide diversity $(\pi)$. Pairwise genetic differentiation using the index $\Phi S T$ between sampling sites were estimated using the software ARLEQUIN 3.5.2.2 [18] with pairwise difference as the distance method and 20,000 permutations. ARLEQUIN was also used to perform a Mantel test to evaluate a pattern of isolation by distance. Tajima's $(D)$ [19] and Fu's $(F s)$ [20] tests were conducted in DnaSP to assess neutrality and as a first estimate of potential population sizes changes in the past. All analyses were run under the $\mathrm{HKY}+\mathrm{G}$ model which was the best nucleotide substitution model determined with jModelTest 2.1.10 [21]. A Maximum Parcimony tree was constructed with the MEGA program [22], with Asian elephant (Genbank: DQ316068.1; NC_005129.2; EF588275.2) as outgroup. The robustness of the phylogenetic inference was assessed using 1000 bootstrap replicates. Genetic differentiation between populations was assessed by comparing the average number of pairwise differences between populations, within populations ( $\mathrm{PiX}$ and $\mathrm{PiY})$ and the corrected average pairwise difference (PiXY_(PiX pPiY)/2), respectively, using the program ARLEQUIN 3.5.2.2 [18]. The significance of differentiation between pairs of populations was tested by exact test [23] using 10,000 Markov chain steps. The frequency of the distributions of pair-wise differences between sequences (mismatch distribution) [24] and neutrality tests $[19,20]$ were examined to test the historical changes in effective population size of forest elephant. Both the mismatch distribution and neutrality tests were performed using the programmes Arlequin 3.5 and DnaSP 6. To investigate the genetic structure, we used the modelbased clustering method implemented in STRUCTURE version 2.3.4 [25]. We tested different numbers of genetic clusters $(K)$ from 1 to 10 . Principal component analysis (PCA) was performed to visualize the haplotype profile of the three subpopulations analyzed.

\section{Results}

\section{Genetic diversity and haplotype frequency}

The alignment of 101 sequences $(600 \mathrm{bp})$ of the mitochondrial D-loop gene of forest elephants of Côte d'Ivoire yielded 53 polymorphic sites and 31 haplotypes. Haplotype diversity was Hd: $0.863 \pm 0.019$ and the value of Nucleotide diversity, Pi (Jukes-Cantor): 0,00416. Haplotypes Hap01 had the highest relative frequency (i.e. $48.94 \%, 23$ out of 47 samples) followed by haplotype Hap3 (i.e. $34.04 \%$, 16 out of 47 samples). 
More than half (16 out of 31 ) of the haplotypes were singletons. No haplotype was shared between the Bossématié FR and the other two sites (Dassioko and Port Gauthier FR) whereas the two later sites shared 5 haplotypes (Fig. 1 and 2). The detail on the frequency, distribution of the identified haplotypes is indicated on Table 1. Haplotype Hap3 has been identified in an elephant kept in the zoo of Abidjan indicating that this individual originated from the Bossématié FR.

Although the Bossématié FR did not share any haplotype with the Dassioko and Port Gauthier FR, the delineation between some of these haplotypes is weak. For example, only one mutational step separates the haplotype Hap3 (unique to Bossématié) to haplotype Hap11 cooccurring in Dassioko and Port Gauthier FRs (Fig. 1 and 2).

\section{Population structure}

The Bayesian model-based clustering approach with STRUCTURE indicated that two clusters $(\mathrm{K}=2)$ provide the most probable representation of the overall genetic structure of the forest elephant populations analyzed (Fig. 3). Forest elephant of Bossématié FR formed a distinct cluster from the populations of Dassioko and Port Gauthier FRs at $\mathrm{K}=2$. There was a positive but non-significant correlation between genetic and geographic distances (Spearman's R Correlation Test: $\mathrm{r}=0.97$; $\mathrm{P}$ - value $=0.37>0.05$ ).

The populations of forest elephant considered as a whole exhibited strong differentiation (Fst $=$ 0.265 , Snn $=0.806$, p-value $=0.00<0.05$ ). When comparing the three subpopulations, significant genetic differenciation was observed either between the subpopulation of Bossématié and Dassioko Fst $=0.271>0.251, \mathrm{p}$-value $=0.0<0.05$ ) or Bossématié and Port Gauthier FRs $($ Fst $=0.375>0.251, p$-value $=0.0<0.05)($ Table 2$)$. A low genetic differentiation was observed between Dassioko and Port Gauthier FRs $(F s t=0.03$, p-value $=0.22>0.05)$, suggesting the existence of genetic exchanges between these populations.

When grouping the populations according to their geographic origins, the analysis of molecular variance (AMOVA) indicated that the majority of the total genetic variance $(73.55 \%)$ occurred within populations and at lesser extent among populations (26.45\%). A highly significant differentiation was observed within populations ( $F s t=0.265, p=0<0.05)$ (Table 3 ). The same trends are observed when populations are grouped into two clusters based on Bayesian clustering. With that clustering the AMOVA analysis indicated that $69.95 \%$ of the genetic variance occurred within populations and $30.05 \%$ of the variance occurred among populations. A significant genetic differentiation (Fst value $=0.30053, \mathrm{p}=0<0.05$ ) was observed within subpopulations as indicated by AMOVA analysis.

Principal coordinate analysis (PCoA) was performed to determine the number of clusters based on Fst values and genetic distance between all pairs of individuals. The multidimensional scaling (MDS) analysis based on the pair matrix of population Fst values clearly showed a relative subdivision of the genetic distances of the three populations into two groups (Figure 4). The group formed by the populations of Dassioko and Port Gauthier FRs seems to clearly separate the two later populations from the group formed by the population of Bossématié FR. The subpopulations of Dassioko and Port-Gauthier seem genetically less distant compared to that of the Bossématié FR.

The phylogenetic analysis revealed that the populations analyzed appear monophyletic, with a general structuring, in a clade. Each cluster was composed of individuals from different populations, which agreed with low inter-population genetic differentiation (Fig. 5).

\section{Historical demography}

Neutrality tests, either by the Fs value of $\mathrm{Fu}$ and $\mathrm{Li}$ and the $\mathrm{D}$ value of Tajima's are negative (Table 4). These tests are however significant for the population of Bossématié FR (Tajima's $\mathrm{D}=-2.481, \mathrm{p}=0.0, \mathrm{Fu}=-1.251, \mathrm{p}=0.31$ ) and DFR (Tajima's $\mathrm{D}=-1.845, \mathrm{p}=0.017, \mathrm{Fu}=-6.115$, 
$\mathrm{p}=0.002)$ and not significant for the population of Port Gauthier FR according to the Tajima's Test (Tajima's $\mathrm{D}=-1.55, \mathrm{p}=0.052$ ) (Table 4). On the other hand, according to the $\mathrm{Fu}$ and $\mathrm{Li}$ Test, the neutrality test was significant for the populations of Dassioko FR (Fs $=-6.115$, $\mathrm{p}=0,002)$ and Port Gauthier FR $(\mathrm{Fs}=-5.332, \mathrm{p}=0.0)$ and not for the one of Bossématié FR ( $\mathrm{Fs}=-$ $1.251, \mathrm{p}=0.31)$ (Table 4).

The analysis of the demographic history of the populations analyzed showed that the distribution of the observed number of pairwise difference between haplotypes simulated according to the population growth model indicate an unimodal curve with respective values of R2 of 0.052 and 0.087 within Dassioko FR and Port Gauthier FR populations respectively (see supplement material). On the other hand, the data simulated according to the demographic expansion model gives a multimodal distribution with a value of $\mathrm{R} 2=0.09$ obtained at within the Bossématié FR population (see supplement material).

These results indicated a demographic change in these subpopulations, indicating that the BFR elephant population is more balanced compared to those of Dassioko and Port Gautier FRs (see supplement material). Furthermore, these demographic parameters show that elephant population of Bossématié FR has experienced recent population expansion, unlike those of the Dassioko and Port Gauthier FRs.

However, the Raggedness statistic (r), was not significant, and therefore did not support the hypothesis of the expansion of forest elephant populations in the studied areas: Bossématié FR $(\mathrm{r}=0.12, \mathrm{p}>0.05)$, Dassioko FR $(\mathrm{r}=0.021, \mathrm{p}>0.05)$ and Port Gauthier FR $(\mathrm{r}=0.12, \mathrm{p}>0.05)$ (Table 4). Thus, suggesting that these populations have remained stable.

\section{Discussion}

This study provided the first examination of the population genetic structure of forest elephant in Côte d'Ivoire. An average nucleotide diversity of $3.5 \%$ was observed in the mitochondrial DNA control region of the studied populations. This value is higher than that reported by Nyakaana et al. [26] within savanna elephants in Zimbabwe and by Fernando et al. [27] within Asian elephants $(1.8 \%)$. This value is however lower than these reported in several studies using the same marker; for example, in Grant's gazelle (6.2\%, [28] and African buffalo (5.0\%, [29]. Relative to the low level of genetic diversity observed, haplotypic diversity was high (0.757). The low level of nucleotide diversity and the high level of haplotypic diversity generally indicate a small effective population size and could also be the result of founder effect and bottlenecks $[10,26]$.

More than half (16 of 31) of the haplotypes observed were singletons and only the Dassioko and Port Gauthier FRs shared the same haplotypes (Hap11, Hap15, Hap16 and Hap23). These can either be shared ancestral haplotypes or/and indicative of recent gene flow exchanges [30] and thus indicate their ancestral origins and a strong connectivity between elephant populations of these two forests. Furthermore, this shows that gene flow occurs between these two populations, unlike the population of Bossématié FR which did not share any haplotype with these two populations. The Dassioko and Port Gauthier FRs are located in the same region (Gboklê) and are separated by $41 \mathrm{~km}$. The proximity of the elephant populations of these two forests and the possible connecting corridors between them enable gene flow between elephant populations.

The strong connection between elephant populations of Dassioko and Port Gauthier FRs is partly supported by the grouping of these populations in the same cluster by both the Bayesian and principal component analyses. In addition, the low levels of genetic divergence separating 
these two populations compared to the genetic divergences separating them from the population of Bossématié FR supports the strong genetic connectivity between the populations of Dassioko and Port Gauthier FRs.

The high gene flows between these two populations certainly decreased or prevented the geographic differentiation between the whole populations studied. Indeed, the results of the Mantel test indicated a lack of correlation between genetic and geographic distances. Similar results were obtained by Nyakaana and Arctander [14] in savanna elephants in Uganda. The ability of elephants to travel long distances and to adapt to various ecological niches has certainly affected such a structuring of the populations studied. This lack of structuring is also supported by the phylogenetic tree and the haplotype network. Indeed, phylogenetic inferences and the haplotype network showed a star-shaped topology with a high rate of singletons. This is generally interpreted as indicative of a population that has recently increased in size from a small number of founders as a result of a population bottleneck [31].

These assertions are in contradiction with the strong genetic divergence separating the Bossématié population from those of Dassioko and Port Gauthier. This disproportionality could be explained by several factors. Indeed, although a relatively large geographical distance separates Dassioko and Port Gauthier FRs with that of Bossématié FR (about $250 \mathrm{~km}$ ), it does not constitute a barrier for elephants. However, the strong human induced disturbance (plantations, human settlements, roads, ...) of the lands separating these forests could limit genetic exchanges between elephant populations. Indeed, elephant movements are not random but are determined by various factors including human activities [32]. Thus, the high levels of fragmentation of protected areas where elephants have survived strongly contributed to the limitation of gene flow when there is no direct proximity that can promote gene exchanges, as have demonstrated the Dassioko and Port Gauthier FRs. This is supported by the AMOVA analysis and the Snn statistic [33] which showed significant genetic differentiation between the studied populations. Habitat fragmentation has led to the reproductive isolation of the elephant populations studied, with a more pronounced effect between the populations of the Bossématié FR and those of Dassioko and Port Gauthier FRs based on the non-significance of the Raggedness statistic ( $r$ ).

The demographic history of the studied populations indicates that they have remained stable during their evolutionary history. However, despite the relatively high genetic diversity indices observed in these populations, the strong decrease in their size could affect their survival in the near future, in the absence of gene flows between them.

The high levels of intra-population and inter-population genetic diversity observed indicate that there was a relatively large elephant population in these different forests. A significant portion of the old gene pools seem to be still maintained in the present populations despite the large reduction in their size. This is an encouraging result for the conservation of this critically endangered species. Despite recent disturbances caused by poaching pressure and the fragmentation of the habitats of these pachyderms, their populations have maintained a sufficient level of genetic diversity. Indeed, the fragmentation of the habitat of these animals leads to their isolation into subpopulations, thus reducing gene flow [34].

\section{Implication for conservation}

Forest elephant populations have sharply declined in their size and numbers over the past decades and the species is now Critically Endangered. The survival of the species now constitutes a great challenge for conservationists. Indeed, the main objective of the conservation of an endangered species is to increase the effective size of its population by maintaining gene flows and its overall genetic diversity. Any strategy for the sustainable conservation of forest elephant populations should therefore integrate the genetic approach. 
Our study has shown that elephant populations of the Dassioko, Port Gauthier and Bossématié FRs are structured into two distinct genetic groups, although these populations share the same evolutionary lineage as indicated by the phylogenetic tree. The sharing of several haplotypes between the populations of Dassioko and Port Gauthier showed the existence of a genetic corridor between these two populations as opposed to the population of Bossématié which remains isolated. However, the genetic corridor connecting the Dassioko and Port Gauthier FRs remains seriously threatened given the current presence of human activity (plantations, human settlements and road infrastructure) all along that corridor. The long-term survival of these two sub-populations will therefore depend on the maintenance and restoration of that corridor, given the small size of the remaining populations. The situation remains more worrying for the forest elephant population of the Bossématié FR which, in addition to its small size, remains geographically isolated. A genetic corridor should therefore be established for the benefit of that population. In Côte d'Ivoire, the Bossématié FR is located at the vicinity of several other protected areas such as Yaya and Mabi FRs. Unfortunately, forest elephant has been locally extirpated from these forests. A genetic corridor should be established on the border of neighboring Ghana where there are several protected areas (Krokosua National Park, Boin NP) inhabiting forest elephant that are located near the Bossématié FR. Indeed, maintaining genetic connectivity between protected areas is crucial for the long-term survival of species [35].

Recent surveys by Kouakou et al. [5] reported the presence of forest elephant in the Tai National Park and of some isolated individuals in communities forests. A complete profile of the genetic structure of forest elephants in Côte d'Ivoire should include these populations. The survival of individuals isolated in the vicinity of plantations depends solely on their reintroduction into the populations living in protected areas. In addition to ensuring the survival of these individuals, this reintroduction will genetically enrich the host populations.

\section{Conclusion}

The analysis of the sequences of the mitochondrial DNA control region of forest elephant populations of Bossématié, Dassioko and Port Gauthier FRs indicated a strong genetic connectivity between the last two populations. Our study revealed a high genetic differentiation between the populations of Bossématié FR and those of the other two forests, indicating a low gene flow between these subpopulations, probably due to their strong fragmentation and geographic isolation.

Although the studied populations of Loxodonta cyclotis still exhibit a relatively high genetic diversity, habitat fragmentation has already had negative consequences on the genetic variability of the remaining populations. Urgent conservation measures are needed to avoid genetic drift and inbreeding depression that could resolutely lead to the reduction of their viability. A strategy aiming to increase the size of forest elephant populations through strengthening measures to protect the remaining populations is needed. A strong genetic connectivity was found between the populations of Dassioko and Port Gaurthier FRs. That connectivity certainly contributed to the relatively high genetic diversity found within these populations and certainly gives them a selective advantage compared to forest elephant population of Bossématié. The viability of this later population appears very fragile given its isolation and the strong reduction of its size.

\section{Acknowledgments}

We are grateful to the Minister of Scientific Research of Côte d'Ivoire for the research permit and the Swiss Centre of Scientific Research for the logistical support that they offered. We are also grateful to the SODEFOR (Société de Développement des Forêts) and the OIPR (Office Ivoirien des Parcs et Réserves) for the permit to access the protected areas. We thank the local communities around the surveyed forests and the field guides for their assistance. 


\section{Author contributions}

GBS conceived the research idea and designed the experiments, analyzed the data, and wrote the manuscript. KJL collected samples, performed the experiments and wrote the manuscript.

\section{Funding}

No funding was received for conducting this study.

Data availability Sequence data have been submitted to GenBank.

Code availability Sequence references have been attributed by GenBank and will soon be available.

\section{Conflicts of interest}

The authors declare no conflict of interest.

\section{References}

1. Boucher D, Elias P, Lininger K, May-Tobin C, Roquemore S, Saxon E (2011) The root of the problem. What is driving tropical deforestation today ? Tropical Forest and Climate Initiative Union of Concerned Scientists. Cambridge: UCS Publications

2. Thouless C, Holly TD, Blanc JJ, Skinner DP, Daniel TE, Taylor RD, Fiona M, Howard F, Philipe B, (2016) «African elephant status report 2016 ». An update from the African Elephant Database

3. Hartley AJ, Nelson A, Mayaux P, Grégoire JM (2000) «The assessment of African protected areas ». Journal of Biogeography 31: 861-77

4. Lindsey PA, Petracca LS, Funston PJ, Bauer H, Dickman A, Everatt K, Flyman M, Henschel P, Hinks AE, Kasiki S (2017) «The performance of African protected areas for lions and their prey ». Biological Conservation 209: 137-49

5. Kouakou J-L, Gonedelé BS, Bitty EA, Kouakou C, Yao AK, Kouadio BK, Soulemane O (2020) « Ivory Coast without Ivory: Massive Extinction of African Forest Elephants in Côte d'Ivoire ». Édité par Bi-Song Yue. PLOS ONE 15 (10): e0232993

6. Roth HH, Douglas-Hamilton I (1991) «Distribution and status of elephants in West Africa ». Mammalia 55 (4): 489-527

7. Allendorf FW, Gordon L (2009) Conservation and the genetics of populations. John Wiley \& Sons

8. Allendorf FW, Luikart G, Aitken SN (2013) Conservation and the genetics of populations. Wiley. Blackwell, Oxford

9. Friesen VL, Burg TM, McCoy KD (2007) « Mechanisms of population differentiation in seabirds ». Molecular Ecology 16 (9): 1765-85

10. Avise JC (2000) Phylogeography: the history and formation of species. Harvard university press

11. Domingues VS, Claudia F, Sergio S, Ricardo SS, Alberto B, Vitor CA (2007) «Genetic divergence in the Atlantic-Mediterranean Montagu's blenny, Coryphoblennius galerita (Linnaeus 1758) revealed by molecular and morphological characters ». Molecular Ecology 16 (17): 3592-3605

12. Amos W (1991) «Long-term skin preservation of whale skin for DNA analysis ». Rep Int Whaling Comm Spec. Issue 13: 99-103

13. Benbouza H, Jean-Pierre B, Guy M (2006) «Amélioration de la méthode d'extraction d'ADN au CTAB appliquée aux feuilles de cotonnier ». Biotechnologie, agronomie, société et environnement 10 (2): 73-76 
14. Nyakaana S, Arctander P (1999) «Population genetic structure of the African elephant in Uganda based on variation at mitochondrial and nuclear loci: evidence for male-biased gene flow ». Molecular Ecology 8 (7): 1105-15

15. Sanger F, Steven N, Alan RC (1977) «DNA sequencing with chain-terminating inhibitors ». Proceedings of the National Academy of Sciences 74 (12): 5463-67

16. Thompson JD., Desmond GH, Toby JG (1994) «CLUSTAL W: improving the sensitivity of progressive multiple sequence alignment through sequence weighting, position-specific gap penalties and weight matrix choice ». Nucleic acids research 22 (22): 4673-80

17. Rozas J, Ferrer-Mata A, Sánchez-DelBarrio JC, Guirao-Rico S, Pablo L, Ramos-Onsins SE, Sánchez-Gracia A (2017) «DnaSP 6: DNA sequence polymorphism analysis of large data sets ». Molecular biology and evolution 34 (12): 3299-3302

18. Excoffier L, Heidi EL (2010) «Arlequin suite ver 3.5: a new series of programs to perform population genetics analyses under Linux and Windows ». Molecular ecology resources 10 (3): 564-67

19. Tajima F (1989) «Statistical method for testing the neutral mutation hypothesis by DNA polymorphism. » Genetics 123 (3): 585-95

20. Fu Y-X (1997) "Statistical tests of neutrality of mutations against population growth, hitchhiking and background selection ». Genetics 147 (2): 915-25

21. Darriba D, Guillermo LT, Ramón D, David P (2012) «jModelTest 2: more models, new heuristics and parallel computing ». Nature methods 9 (8): $772-772$

22. Kumar S, Glen S, Michael L, Christina K, Koichiro T (2018) «MEGA X: molecular evolutionary genetics analysis across computing platforms ». Molecular biology and evolution 35 (6): 1547-49

23. Raymond M, François R (1995) « An exact test for population differentiation ». Evolution, 1280-83

24. Schneider S, Excoffier L (1999) «Estimation of past demographic parameters from the distribution of pairwise differences when the mutation rates vary among sites: application to human mitochondrial DNA ». Genetics 152 (3): 1079-89

25. Pritchard JK, Matthew S, Peter D (2000) «Inference of population structure using multilocus genotype data ». Genetics 155 (2): 945-59

26. Nyakaana S, Arctander P, Siegismund HR (2002) «Population structure of the African savannah elephant inferred from mitochondrial control region sequences and nuclear microsatellite loci ». Heredity 89 (2): 90-98

27. Fernando P, Michael E. P, Sandra EE, Russell L (2000) «Mitochondrial DNA variation, phylogeography and population structure of the Asian elephant ». Heredity 84 (3): 362-72

28. Arctander P, Kat PW, Simonsen BT, Hans RS (1996) «Population genetics of Kenyan impalas-consequences for conservation ». Molecular genetic approaches in conservation, 399-412

29. Simonsen BT., hans RS, Arctander P (1998). «Population structure of African buffalo inferred from mtDNA sequences and microsatellite loci: high variation but low differentiation ». Molecular Ecology 7 (2): 225-37

30. Avise J., Jonathan A, Martin BR, Eldredge B, Trip L, Joseph EN, Carol AR, Nancy C S (1987) « Intraspecific phylogeography: the mitochondrial DNA bridge between population genetics and systematics ». Annual review of ecology and systematics 18 (1): 489-522

31. Slatkin M, Richard RH (1991) «Pairwise comparisons of mitochondrial DNA sequences in stable and exponentially growing populations. » Genetics 129 (2): 555-62

32. Barnes RFW, Barnes KL, Alers MPT, Blom A (1991) «Man determines the distribution of elephants in the rain forests of northeastern Gabon ». African Journal of Ecology 29 (1): 54-63 
33. Hudson RR (2000) «A new statistic for detecting genetic differentiation ». Genetics 155 (4): 2011-14

34. Wang M, Arnd S (2001) «The impact of habitat fragmentation and social structure on the population genetics of roe deer (Capreolus capreolus L.) in Central Europe ». Heredity 86 (6): $703-15$

35. Luikart G, Nils R, David AT, Michael KS, Fred WA (2010). «Estimation of census and effective population sizes: the increasing usefulness of DNA-based approaches ». Conservation Genetics 11 (2): 355-73 


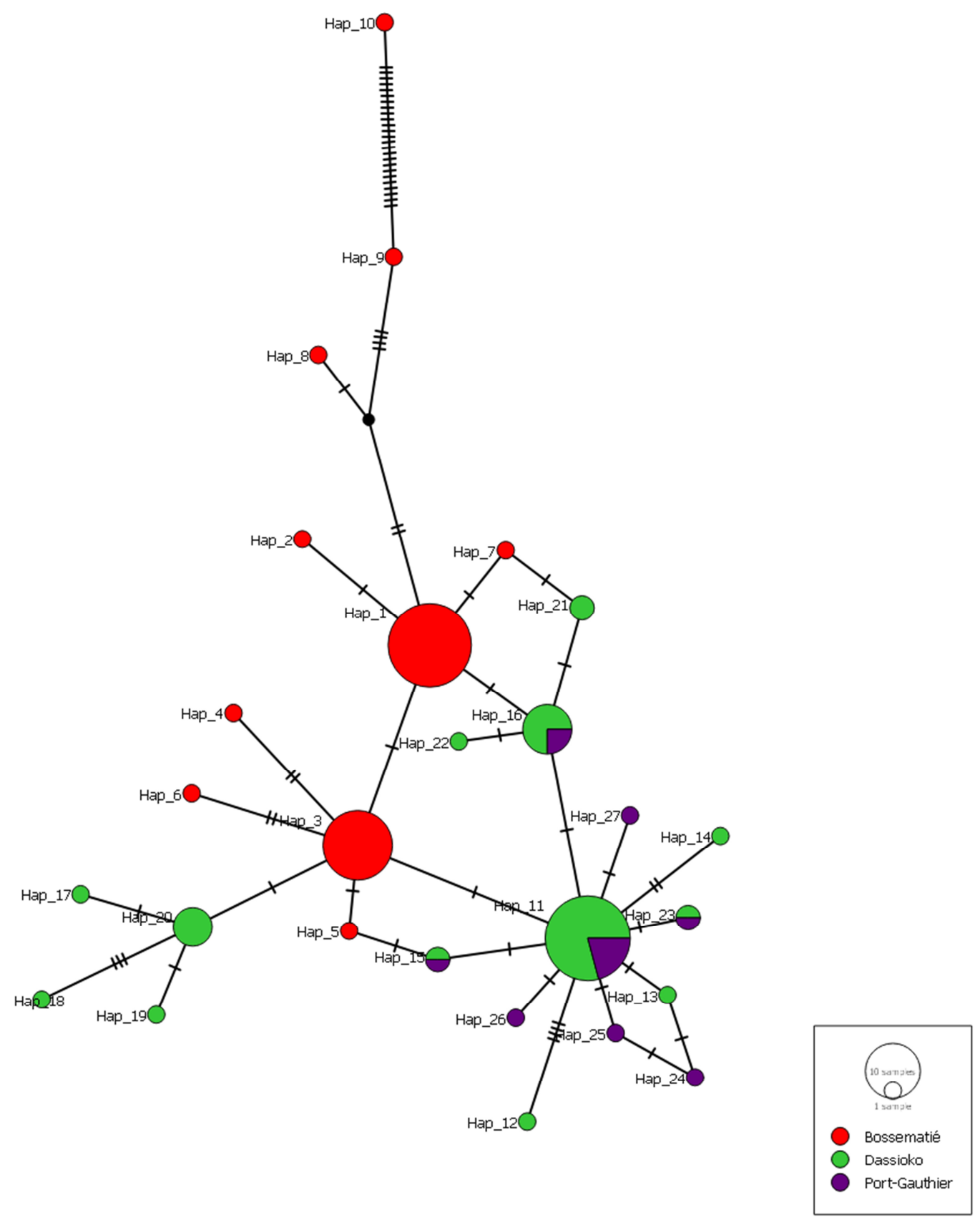

Fig. 1 Haplotype network for the mitochondrial control region of Loxodonta cyclotis. Colours refer to sampling locations. The area of the circles is proportional to each haplotype frequency. In the case where haplotypes are shared among sampling locations, shading is proportional to the requency of the haplotype in each sampling location. 


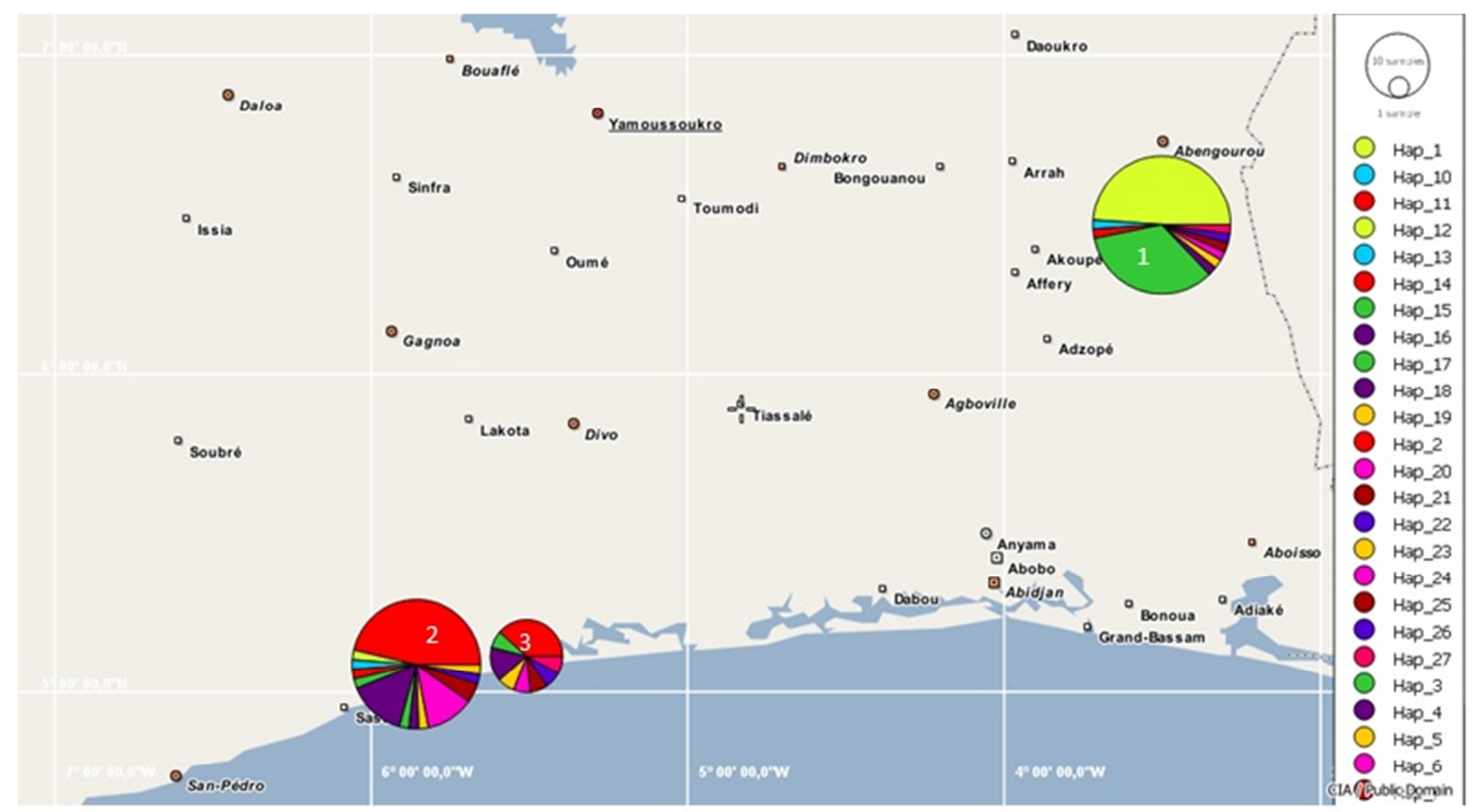

Fig. 2 Distribution of mitochondrial DNA haplotypes across the three forest reserves where dung samples were collected: Bossématié FR (1), Dassioko FR (2) and Port-Gauthier FR (3)

The size of the circles is proportional to the sample sizes in the dataset per study site. 
Table 1 Geographical distribution of mtDNA haplotypes in three locations (Bossématié FR, Dassioko FR, Port Gauthier FR)

\begin{tabular}{|c|c|c|c|c|}
\hline \multirow[t]{2}{*}{ Haplotypes } & \multicolumn{3}{|c|}{$\begin{array}{l}\text { Relative frequencies of haplotypes by } \\
\text { locality }\end{array}$} & \multirow[t]{2}{*}{$\begin{array}{l}\text { Number of haplotypes per } \\
\text { individual }\end{array}$} \\
\hline & FCB & FCD & FCPG & \\
\hline Hap1 & 0.489 & 0 & 0 & 23 \\
\hline Hap2 & 0.0213 & 0 & 0 & 1 \\
\hline Hap3 & 0.34 & 0 & 0 & 16 \\
\hline Hap4 & 0.0213 & 0 & 0 & 1 \\
\hline Hap5 & 0.0213 & 0 & 0 & 1 \\
\hline Hap6 & 0.0213 & 0 & 0 & 1 \\
\hline Hap7 & 0.0213 & 0 & 0 & 1 \\
\hline Hap8 & 0.0213 & 0 & 0 & 1 \\
\hline Hap9 & 0.0213 & 0 & 0 & 1 \\
\hline Hap10 & 0.0213 & 0 & 0 & 1 \\
\hline Hap11 & 0 & 0.463 & 0.385 & 24 \\
\hline Hap12 & 0 & 0.0244 & 0 & 1 \\
\hline Hap13 & 0 & 0.0244 & 0 & 1 \\
\hline Hap14 & 0 & 0.0244 & 0 & 1 \\
\hline Hap15 & 0 & 0.0244 & 0.0769 & 2 \\
\hline Hap16 & 0 & 0.146 & 0.154 & 8 \\
\hline Hap17 & 0 & 0.0244 & 0 & 1 \\
\hline Hap18 & 0 & 0.0244 & 0 & 1 \\
\hline Hap19 & 0 & 0.0244 & 0 & 1 \\
\hline Hap20 & 0 & 0.122 & 0 & 5 \\
\hline Hap21 & 0 & 0.0488 & 0 & 2 \\
\hline Hap22 & 0 & 0.0244 & 0 & 1 \\
\hline Hap23 & 0 & 0.0244 & 0.0769 & 2 \\
\hline Hap24 & 0 & 0 & 0.0769 & 1 \\
\hline Hap25 & 0 & 0 & 0.0769 & 1 \\
\hline Hap26 & 0 & 0 & 0.0769 & 1 \\
\hline Hap27 & 0 & 0 & 0.0769 & 1 \\
\hline
\end{tabular}


Table 2 Matrix of pairwise Fst of the three subpopulations of forest elephants studied (Fst total $=0.265 \%, \mathrm{p}=0<0.05)$.

\begin{tabular}{llll}
\hline & FC Bossématié & FC Dassioko & FC Port-Gauthier \\
\hline FC Bossématié & - & & \\
FC Dassioko & $0.271^{0.0^{* * *}}$ & - & - \\
FC Port-Gauthier & $0.375^{0.0^{* * *}}$ & $0.03^{\mathrm{ns}}$ & - \\
\hline
\end{tabular}


Table 3 Analyses of molecular variance (AMOVA) in Loxodonta cyclotis in Côte d'Ivoire inferred from mitochondria control region

\begin{tabular}{|c|c|c|c|c|c|}
\hline Source of variation & $\begin{array}{l}\text { Sum of } \\
\text { squares }\end{array}$ & $\begin{array}{l}\text { Variance } \\
\text { components }\end{array}$ & $\begin{array}{l}\text { Pourcentage } \\
\text { of variation } \\
(\%)\end{array}$ & $\begin{array}{l}\text { F- } \\
\text { statistics }\end{array}$ & P-values \\
\hline \multicolumn{6}{|c|}{ Three populations based on their geographic origin } \\
\hline $\begin{array}{l}\text { Among } \\
\text { populations }\end{array}$ & 24.475 & 0.36875 & 26.45 & & \\
\hline Within populations & 100.475 & 1.02526 & 73.55 & 0.265 & $<0.0001$ \\
\hline Total & 124.950 & 139401 & 100 & & \\
\hline \multicolumn{6}{|c|}{ Two populations based on Bayesian clustering } \\
\hline Inerpopulations & 23.217 & 0.44152 & 30.05 & 0.30053 & $<0.0001$ \\
\hline Intrapopulations & 101.733 & 1.02761 & 69.95 & & \\
\hline Total & 124.950 & 1.46913 & 100 & & \\
\hline
\end{tabular}


Table 3 Genetic diversity and neutrality tests of the mitochondrial D-loop of forest elephant of Côte d'Ivoire

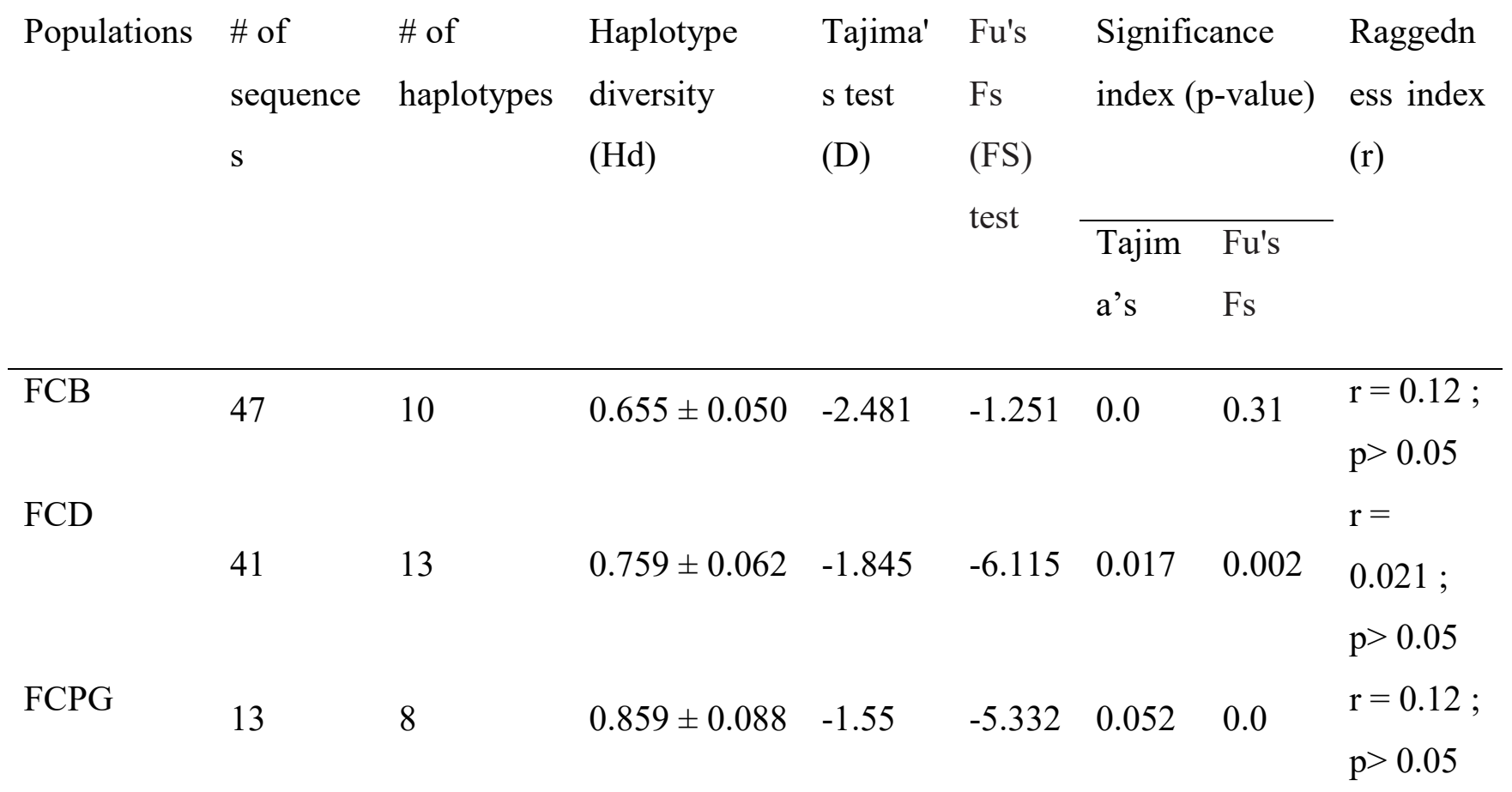



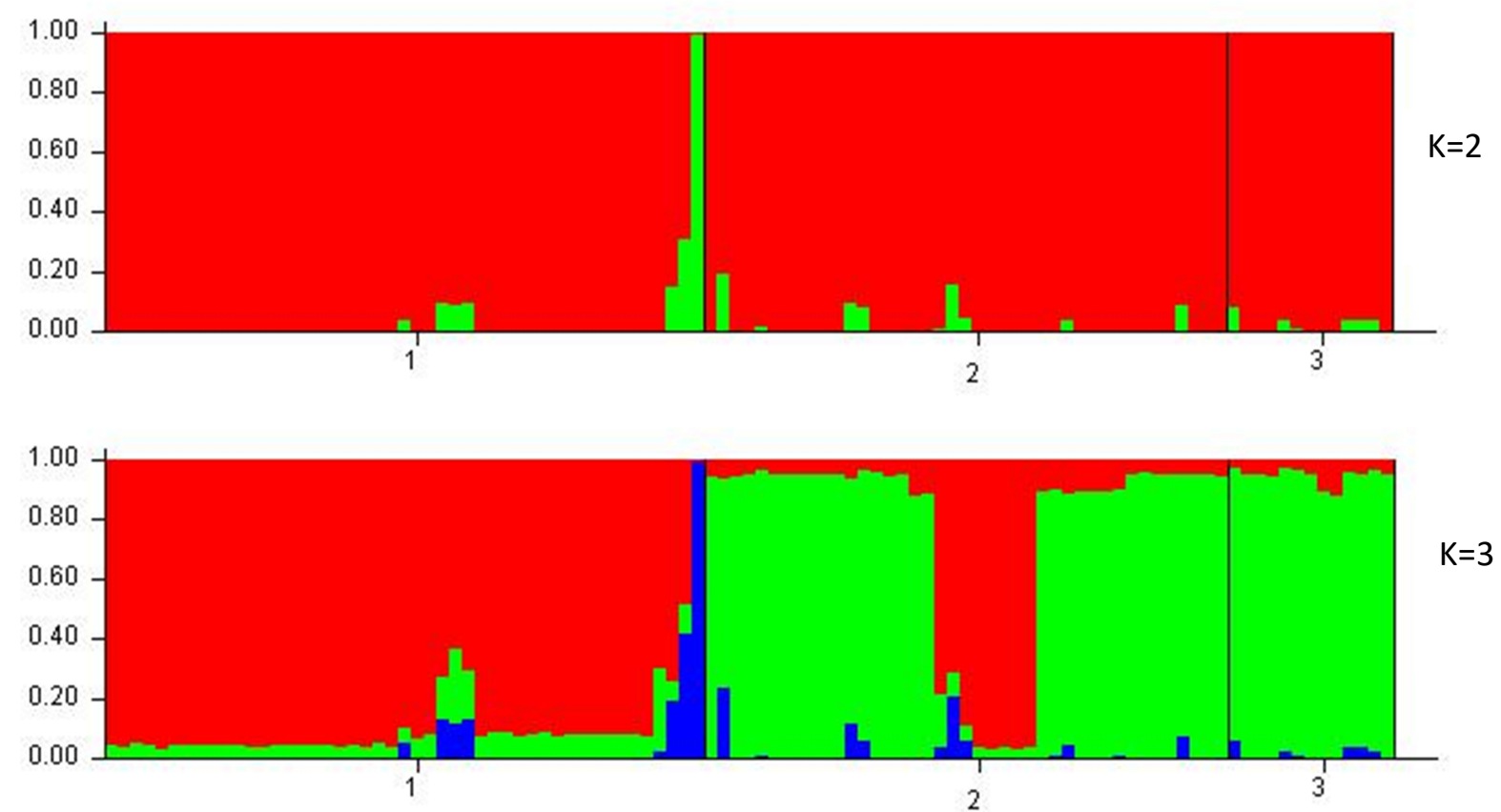

Fig. 3 Population assignment of individuals (vertical lines) to putative population clusters based on Bayesian analysis of population structure (STRUCTURE software version 2.3.4) for cmitochondrial D-loop region of Loxodonta cyclotis in Côte d'Ivoire

Each node (line on the branches) corresponds to a mutation. The letters represent the haplotypes and the size of the circles is proportional to the frequency of the haplotypes. The colors of the haplotype pie charts correspond to the proportion of haplotype appearances in the different forests sampled.

1: Dassioko FR; 2: Port Gauthier FR; 3: Bossématié FR. 


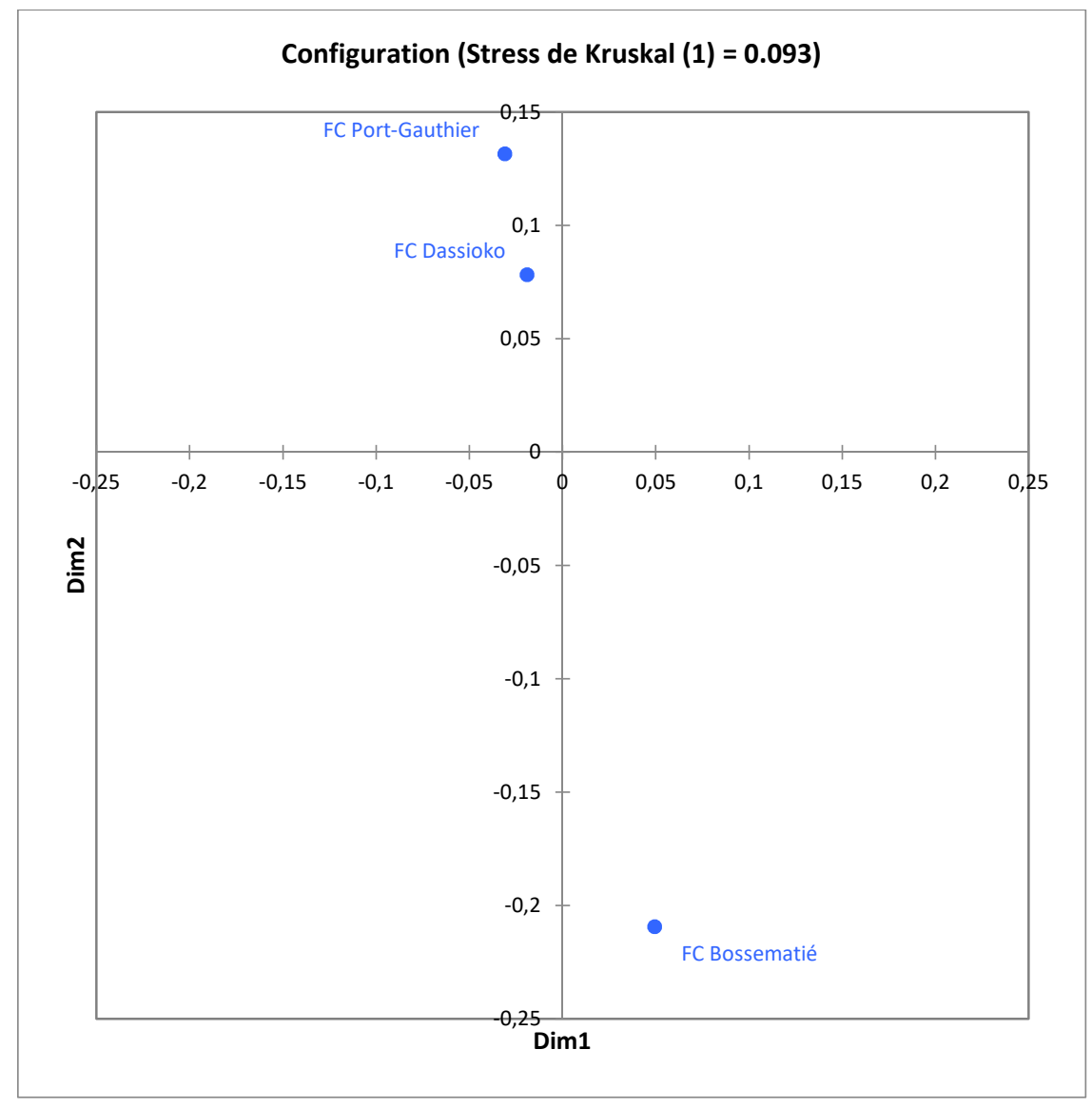

Fig. 4 Principal coordinate analysis (PCoA) for Loxodonta cyclotis based on the comparison of pairwise Fst of three populations of forest elephant in Côte d'Ivoire 


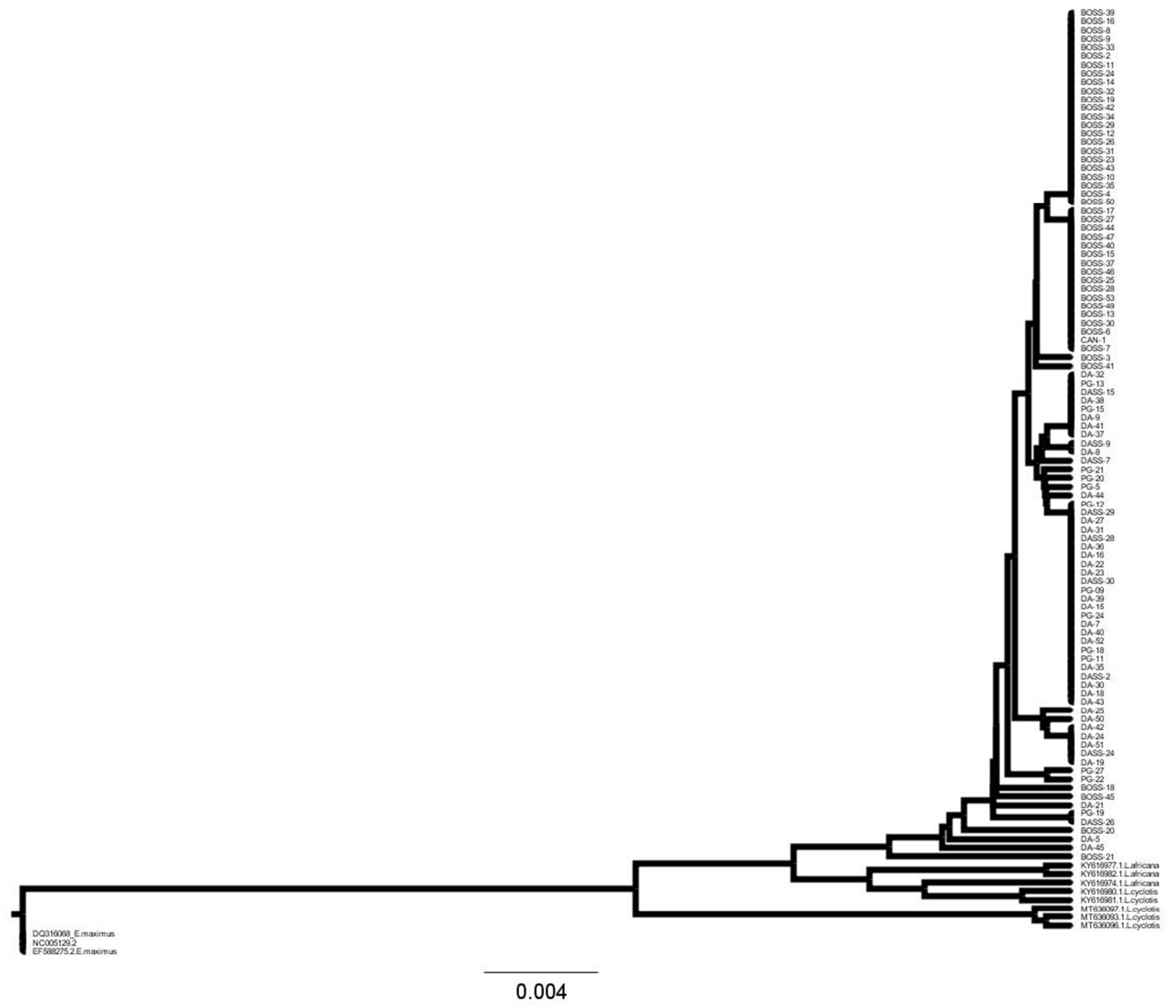

Fig. 5 Phylogenetic relationships of forest elephant population of Côte d'Ivoire based on 27 haplotypes derived from 102 mitochondrial DNA control region sequences measuring 600 base pairs, inferred from maximum likelihood method. The numbers above the branches indicate the bootstrap values with 1000 replicates (NeighborJoining), under the HKY $+\mathrm{G}$ evolution model. 